\title{
V8 - DEVELOPMENT OF CAPILLARY ELECTROPHORESIS METHOD FOR DETERMINING FREE PROTEIN CONTENT IN A BRAZILIAN MENINGOCOCCAL C CONJUGATE VACCINE
}

$\underline{\text { Iaralice Medeiros de Souza }}{ }^{1}$, Milton Neto da Silva $^{1}$, Elza Cristina Scott Figueira ${ }^{1}$, Maria de Lourdes Moura Leal ${ }^{1}$, Ellen Jessouroun ${ }^{1}$, Shirley de Mello Pereira Abrantes ${ }^{2}$, Ivna Alana Freitas Brasileiro da Silveira ${ }^{1}$.

${ }^{1}$ Laboratory of Bacterial Technology, Technological Development, Bio-Manguinhos, Oswaldo Cruz Foundation

2 Laboratory of Foodstuffs and Contaminants, Department of Chemistry, National Institute of Quality Control in Health, Oswaldo Cruz Foundation

Objectives: This study aims the development of a method for free protein separation and quantitation in the meningococcal $\mathrm{C}$ conjugate vaccine developed by Bio-Manguinhos, in accordance with WHO requirements.

Methods: Capillary electrophoresis (CE) was used for method development where micellar electrokinetic chromatography (MEKC) and free zone capillary electrophoresis (CZE) were the modes tested. In both modes sodium tetraborate buffer (TBNa) and uncoated fused-silica were used for analysis. For MEKC mode analysis, sodium dodecyl sulfate was used to form micelles and improve separation resolution. In CZE experiments, samples were analyzed in two ways: only with buffer and adding different concentrations of diamine, a capillary wall modifier, in order to promote vaccine components separation. Different parameters such as: temperature, electric current, voltage, buffer concentration, $\mathrm{pH}$ and sample volume were tested in both CE modes. Vaccine conjugate bulk (MPCT), hidrazide-activated monomeric tetanus toxoid (MATT), MPCT spiked with MATT and oxidized meningococcal C polysaccharide (MPCO) samples were introduced into capillary using MEKC and CZE modes, in order to obtain optimum separation resolution and evaluate method selectivity.

Results: After optimization of analysis parameters, assays performed by MEKC were able to discriminate conjugate and free protein peaks, but presented a peak broadening profile with low separation resolution. On the other hand, unknown and characteristic 
conjugate and protein peaks were observed in CZE analysis performed by adding diamines to buffer with uncompleted separation $\left(\mathrm{R}_{\mathrm{s}} \approx 1\right)$. In addition consecutive introduction of MPCT spiked with MATT sample showed migration times unstable. Moreover, in the MPCT analysis by CZE using $20 \mathrm{mM}$ TBNa pH 9.3 was not observed a signal corresponding to MATT. However three peaks (MATT, MPCO and MPCT) with good separation resolution $\left(\mathrm{R}_{\mathrm{s}}>1.5\right)$ were observed when MPCT spiked with MATT sample was introduced suggesting low free protein content in MPCT samples.

Conclusion: CZE mode has shown good efficiency in preliminary separation and quantitation of free protein in conjugate vaccine. However, treatment and conditioning optimization of the capillary would be required to obtain a robust method for quality control process of Brazilian meningococcal $\mathrm{C}$ conjugate vaccine. 